\title{
IMIGRAÇÃO HAITIANA PARA O BRASIL: OS DESAFIOS NO CAMINHO DA EDUCAÇÃO ESCOLAR
}

\author{
HAITIAN IMMIGRATION TO BRAZIL: THE CHALLENGES IN THE WAY OF EDUCATION \\ INMIGRACIÓN HAITIANA PARA BRASIL: LOS DESAFIOS EN EL CAMINO DE LA \\ EDUCACIÓN ESCOLAR
}

Marília Lima Pimentel Cotinguiba

Doutorado em Linguística pela UNESP. Professora da UNIR | Brasil E-mail: mpimentel9@gmail.com

Geraldo Castro Cotinguiba

Doutorando/UNIR em Desenvolvimento Regional e Meio Ambiente. Cientista Social. | Brasil E-mail: mpimentel9@gmail.com

\begin{abstract}
REVISTA PEDAGÓGICA
Revista do Programa de Pós-graduação em Educação da Unochapecó | ISSN 1984-1566 Universidade Comunitária da Região de Chapecó | Chapecó-SC, Brasil Como referenciar este artigo: COTINGUIBA, M. L. P. COTINGUIBA, G. C. Imigração haitiana para o Brasil: os desafios no caminho da educação escolar. Revista Pedagógica, Chapecó, v.17, n.33, p. 61-87, Jul./Dez. 2014.
\end{abstract}

\begin{abstract}
RESUMO: Este artigo tem como objetivo discutir alguns aspectos dos desdobramentos da imigração haitiana para o Brasil, tomando como discussão central a inserção de crianças, adolescentes e adultos no ambiente escolar. A metodologia que temos empregado no curso da nossa pesquisa é a etnografia, valorizando a observação participante. Os resultados aqui apresentados não são conclusivos, mas devem ser considerados iniciais. A nossa reflexão é com base na realidade da cidade de Porto Velho, capital do estado de Rondônia, na Amazônia ocidental brasileira e, em alguns aspectos, sobre dados e vivências que tivemos em outras cidades brasileiras. Por fim, esta reflexão estabelece uma relação e diálogo teóricos com alguns autores a partir de abordagens que contemplam a nossa discussão, os quais aparecerão no momento adequado, assim como nossos trabalhos já realizados.
\end{abstract}

PALAVRAS-CHAVE: Imigração haitiana. Brasil. Ambiente escolar. Burocracia.

\begin{abstract}
This article aims to discuss some aspects of the unfolding of Haitian immigration to Brazil, taking as central discussion the insertion of children, teeneages and adults in the school environment. The methodology that we have used of our research is ethnography, valuing the participant observation. The results presented here are not conclusive, but should be considered early, by given the fact we ignore other studies on the theme. Our thinking is based on the reality of the city of Porto Velho, the capital of Rondônia, in the Brazilian western Amazon and in some aspects, on data and experiences we had in other Brazilian cities. Finally, this reflection establishes a relationship and theoretical dialogue with some authors from approaches that behold our discussion, which will appear at the right time, as well as our previous work
\end{abstract}

KEYWORDS: Haitian Immigration. Brazil. School environment. Bureaucracy. 
*Os resultados que apresentamos aqui são com base em dois projetos de pesquisa, aprovados no Conselho de Ética da Universidade Federal de Rondônia. Agradecemos aos haitianos e aos colegas e alunos brasileiros que trabalham conosco. Não discutiremos a questão da saúde, mas é um tema que necessita de reflexão. A concepção de saúde para os haitianos apresenta características nativas que precisam ser levadas em consideração. Sobre isso veja Beauvoir (2011).
1 Não discutiremos a questão da saúde, mas é um tema que necessita de reflexão. A concepção de saúde para os haitianos apresenta características nativas que precisam ser levadas em consideração. Sobre isso veja Beauvoir (2011).

\section{APRESENTAÇÃO}

Este artigo tem como objetivo inserir a migração haitiana nas discussões sobre educação escolar no Brasil. O argumento para tal proposição é com base nos desdobramentos relativos à entrada de milhares de haitianos no país desde 2010 e os desafios que muitos sujeitos dessa nacionalidade têm encontrado ao tentar inserir-se no sistema educacional formal brasileiro, independente de qual nível seja. As barreiras encontradas pelos haitianos - assim como muitos outros imigrantes - ao buscarem as instituições brasileiras refletem uma problemática que já apontamos, numa outra perspectiva, como a ausência de uma política de imigração no país (Cotinguiba, 2014; Cotinguiba e Pimentel, 2014a) que esteja preparada para pensar a recepção de imigrantes e disponibilizar serviços que atendam suas necessidades burocráticas, especialmente o acesso a direitos sociais, como educação e saúde ${ }^{1}$.

Dividimos este artigo em tópicos que contemplam, de maneira descritiva, diferentes aspectos da educação, de maneira que a discussão que trazemos à tona aqui objetiva uma reflexão que abranja as pessoas e instituições que já desenvolvem trabalhos de atendimento às necessidades educacionais dos haitianos. Ao mesmo tempo, é um convite àqueles que ainda não estão envolvidos neste processo, contudo são, potencialmente, candidatos a desenvolverem relações com haitianos neste âmbito. Assim, este trabalho é mais uma provocação que um direcionamento. Além disso, julgamos pertinente descrever algumas tentativas de inserção dos haitianos no sistema escolar brasileiro presenciadas por nós, ao longo da pesquisa.

Não temos a intenção de esclarecer as demandas, nosso desejo é o de que as informações e reflexões que trazemos possam, de alguma maneira, servir de embasamento ou subsídio. Em relação à presença haitiana no Brasil, a discussão sobre a inserção no ambiente escolar é nova, contudo, não é uma novidade em relação à mesma problemática em outros lugares, como já demonstrado por Cédric Audebert (2005) no caso estadunidense, especificamente em Miami. Dada a dinâmica da imigração haitiana e, ao mesmo tempo, do desenvolvimento de estudos sobre o tema, não podemos fazer afirmações de que não haja trabalhos que contemplem a temática no Brasil.

Temos conhecimento de algumas pesquisas mais amplas que estão em curso em diferentes lugares do Brasil, no entanto a inserção no ambiente escolar não aparece. Este artigo vem como complemento de um outro trabalho (Cotinguiba e Pimentel, 2015) procuramos abordar algumas questões históricas e linguísticas, recortando a nossa vivência com o ensino de português para os haitianos em Porto Velho 
${ }_{2} \mathrm{O}$ projeto a que referimos é coordenado por nós, os autores, pela Universidade Federal de Rondônia, e conta com uma equipe multidisciplinar. $\mathrm{O}$ nome do projeto é Migração internacional na Amazônia brasileira: linguagem e inserção social de haitianos em Porto Velho.

\section{ASPECTOS GERAIS DA CONSTRUÇÃO DESTA PESQUISA}

Ao longo de nossa pesquisa, a tarefa que se apresentou a nós foi multifacetada, como a barreira linguística entre nós e os haitianos, o estranhamento ou o que poderíamos chamar de estratégia de autoproteção dos indivíduos, frente a nós, os estranhos, a nossa inexperiência no tocante a se relacionar com imigrantes e ensinar-lhes a língua portuguesa. Salvo alguns conhecimentos básicos sobre a história do Haiti e da então recente imigração haitiana para o Brasil, nós, literalmente começamos do zero.

Quando da chegada dos primeiros haitianos a Porto Velho, criou-se um mito de um povo falante de várias línguas, com ênfase no francês. Por algum tempo, por mais que tentássemos entender a coexistência do francês e do crioulo haitiano, não conseguíamos. Isso foi, aos poucos, sendo esclarecido para nós com base em muitas conversas com nossos interlocutores, leituras de artigos teóricos e, além de visita à Embaixada haitiana em Brasília. Nesses esforços, o nosso encontro e diálogo com a pesquisadora Renata de Melo Rosa, que passou 6 meses no Haiti foi providencial. A nossa vivência em campo nos deu, pouco a pouco, condições para melhor compreendermos, mesmo que de maneira limitada, questões fundamentais sobre a língua e a formação escolar no Haiti, como mostraremos mais adiante. Daí a importância do projeto de extensão universitária que criamos ${ }^{2}$, por ter sido por meio dele que se deu a nossa entrada em campo e que nos proporcionou um ambiente de entendimento das necessidades e, ao mesmo tempo, um lugar para a pesquisa de campo com observação participante, a partir de uma perspectiva de que um dos objetivos de uma pesquisa em Ciências Humanas é a devolução às pessoas que se permitem ser observadas.

Como sabemos, pela antropologia, por meio da teoria das trocas, em todas as formas de relações sociais a troca é um elemento fundamental e opera, geralmente, numa via de mão dupla e no caráter triplo, o dá, o receber e o retribuir, denominado 'sistema de prestações totais' ou fato social total (Mauss, 2003). Dessa forma, a nossa pesquisa se enquadra na lógica das trocas e o nosso movimento inicial foi o de dá, isto é, começamos 'dando' aulas de língua portuguesa e, ao longo do tempo, recebemos a devolução em forma de informações que nos permitiram escrever sobre essa imigração. Agora estamos na fase da retribuição, com a publicação de artigos científicos e, recentemente, com um livro de ensino de português para haitianos (Cotinguiba, Pimentel e Novaes, 2014).

Quase quatro anos depois de iniciarmos o projeto, podemos afirmar que o nosso lugar se define de maneira clara e nossa imagem está vinculada à nossa atividade 
3 Sobre o ponto de vista de Seguy ver os vídeos na internet, disponível em: $<$ https://www.youtube.com/channel/ Cue13X3w17GXWLGP3CPACNw>. Acesso em 14 abr. 2015. E a tese de doutorado de Seguy (2014). Seguy retornou ao Haiti e é professor de sociologia na Université d'Etat d'Haïti. profissional. Somos, para os haitianos que nos conhecem, assim como para os representantes da Embaixada haitiana, professores e aqueles que realizam trabalhos de cunho humanitário. Gozamos de uma posição que não mais precisamos prestar explicações detalhadas de quem somos, o que fazemos e quais os nossos interesses, sobretudo pelo fato de termos aprendido o crioulo haitiano - salvo exceções. A vivência em campo que tivemos junto aos haitianos se confunde, sobremaneira, com parte da dinâmica migratória desses sujeitos em solo brasileiro. Certamente, as limitações existem e o que queremos dizer é que, desde 2011, tivemos a oportunidade de visitar várias cidades brasileiras, desde o estado do Acre, na fronteira com a Bolívia e o Peru, na Amazônia ocidental brasileira, na região Norte, até o extremo oposto do território brasileiro, na região Sul, no estado do Rio Grande do Sul.

Dentre os diferentes aspectos que estivemos atentos, a educação foi um tema recorrente das nossas observações, conversas, discussões e reflexões. Estudar em outro país é um sonho para muitos haitianos, e essa afirmação não é um exagero. Como nos disse um rapaz, em Porto Velho, externando o que parece ser a tônica de uma mesma retórica que ouvimos em diferentes cidades, a de que "se você só estuda no Haiti você não tem valor, mas se você estudar em outro país, quando volta aí você tem todo respeito”. Essa afirmação deve ser vista com atenção. Não sabemos, ainda, se essa retórica tem como objetivo dizer que é interesse estudar em outro país e retornar ao Haiti ou se é uma forma de dizer que se tem prestígio e respeito perante os demais na dyaspora e ser orgulho da família na origem. Dyaspora, ao mesmo tempo, conceito e categoria. É o movimento de emigração haitiana para os diversos países. Também é a pessoa que emigra. Todo haitiano emigrado é um dyaspora. Pode, também, ser aplicado às coisas inanimadas, àquelas enviadas ou presenteadas por um dyaspora.

A definição de dyaspora que trabalhamos aqui é com base no que ouvimos de nossos interlocutores, contudo, o sociólogo haitiano, Franck Seguy3, concorda parcialmente com essa definição, entretanto a usaremos, mesmo correndo o risco de ser parcialmente contraditória. Por se encontrar no Haiti, entramos em contato com Seguy, via facebook, e solicitamos a ele alguns comentários sobre essa questão e sua resposta foi a que se segue - fomos autorizados a reproduzir seu comentário.

Além do que já falou, o dyaspora se encontra em um país considerado rico. E ganha um salário 'bom'. Por isso, quando voltar de visita ao Haiti, é capaz de ostentar sua nova situação: no uso de roupas caras, de joias, de carrão alugado e sobretudo distribuindo dinheiro aos parentes e amigos. Por exemplo, 
um migrante haitiano que trabalha na República Dominicana não é considerado dyaspo$r a$, pois não há uma notável diferença entre sua situação econômica e a de um haitiano que permanece no Haiti (Franck Seguy, Haiti, 2015)

Como exemplo de seu argumento, Seguy enviou-nos um comentário de um estudante haitiano da Unicamp, que diz que os haitianos que estão no Brasil não são dyaspora como os que estão nos Estados Unidos, Canadá ou França. Vale ressaltar que essa noção de país rico é o que, também, os haitianos chamam de peyi blan, literalmente país branco, que significa um lugar onde se pode ganhar "um salário bom' para ajudar a família. Nesse sentido, para muitos haitianos que estão no Brasil, a situação não se encaixa na de um dyaspora em um peyi blan. Contudo, para outros, sim, pois conseguem enviar dinheiro, viajar, levar presentes e mesmo conseguir trazer a família para o Brasil. Se levarmos para a discussão para o aspecto do sucesso pessoal, mesmo em um peyi blan há os que não conseguem.

Nesse sentido, as pistas indicam que a emigração haitiana é multifacetada e, em relação aos jovens estudantes, não é apenas uma questão de buscar trabalho em outros países, aquilo que se tornou uma classificação do senso comum como 'fuga de cérebros'. Alguns dados estatísticos do quadro educacional haitiano chamam atenção, como o fato de que muitos estudantes, ao terminarem os cursos universitários, emigram para países que tradicionalmente parte população haitiana almeja, como Estados Unidos e Canadá. Como afirma Seguy, não é uma emigração em busca de trabalho apenas, mas por melhores condições de vida. Assim, não são os cérebros que migram, mas pessoas inteiras e os motivos são muitos.

De modo geral, estudar fora do Haiti acrescenta um mais no valor do profissional na hora de competir com alguém da mesma qualificação com ele no mercado. O que, porém, valoriza mais o fato de estudar fora é que há pouco tempo atrás, quase não existia pós-graduação no Haiti. Sem esquecer de que as universidades haitianas não estão entre as melhores do mundo, é claro. A primeira turma de doutores formados no Haiti está para sair somente em 2016. Tudo isso acaba contribuindo para prestigiar mais o diploma obtido no exterior. Isso também faz parte dos motivos da emigração haitiana. Pois a maioria dos haitianos que saem para Europa e a América do Norte para cursar pós-graduação não voltam ao Haiti. Não por acaso que mais de $80 \%$ dos haitianos com diplomas superiores estão hoje fora do Haiti. Somente na província do Quebec, encontram-se mais mé- 
4 As informações que relatamos aqui neste tópico, sobre educação, são com base em material teórico e a partir dos relatos de nossos interlocutores em nossa pesquisa de campo, além de análise de documentos escolares haitianos e contato com a Embaixada da República do Haiti no Brasil. Agradecemos a todos. dicos haitianos do que no próprio Haiti. Também, o Canadá tem uma política de incentivo à migração desses haitianos. Sua embaixada no Haiti tem um programa especial de visto permanente para haitianos detentores de diplomas superiores. Qualquer haitiano nessa condição tem a possibilidade de obter o visto permanente do Canadá já no Haiti antes mesmo de emigrar para o Canadá. É a isso que se dá o nome de "roubo de cérebros". O primeiro capítulo de minha tese aborda essa questão, entre outras (Franck Seguy, Haiti, 2015).

Como podemos notar na fala de Seguy e, de acordo com nossa linha de raciocínio, a questão educacional na vida de muitos haitianos significa uma oportunidade única de ascensão social e reconhecimento em seu país e entre seus familiares, além da oportunidade de ajudar aos que se vinculam. Por não ser o foco central de nossa reflexão, os aspectos da educação em solo haitiano aqui relacionados são trazidos à tona somente para embasar a nossa discussão, para que possamos melhor compreender a relevância da educação para os haitianos que estão no Brasil.

Dessa forma, organizamos este artigo de uma maneira que sua leitura possa oferecer um panorama de aspecto duplo, por um lado uma imagem geral do ambiente educacional no Haiti, tanto da sua forma burocrática ou a maneira como se organiza, abordando alguns elementos da questão linguística. Por outro lado, expomos um quadro geral de nossa vivência no processo da imigração haitiana para o Brasil, com o objetivo de relatarmos e comentarmos brevemente nossas visitas a algumas cidades e, também, trazer para a reflexão os entraves burocráticos pelos quais esses imigrantes são submetidos frente ao ambiente escolar brasileiro. Insistimos que há limitações em nosso trabalho, contudo, elas são um convite para a crítica e a autocrítica.

\section{ASPECTOS SOCIOLÓGICAS - IDENTIDADE, LÍNGUA E EDUCAÇÃO ESCOLAR NO HAITI4}

Qualquer inferência que se faça de uma pessoa, grupo ou sociedade inteira, quando transformados em um outro de um nós, sem um tempo de convivência relativamente adequado é, no mínimo, um senso comum ou, no máximo, um reducionismo refinado por um sofisma retórico academicizado. Perceber o outro é, antes de tudo, um exercício de alteridade, longo, paciente e reflexivo.

O exercício da alteridade é uma via de duas mãos de seres que se pretendem sociais e sociáveis, é troca de empatia. É necessário estarmos aptos para um movimento duplo, o de autopercepção e o da 
5 Optamos por escrever haitiano ao invés de ter de colocar, todas as vezes, a palavra haitiano(a). Dessa forma, entende-se que estamos falando de pessoas e não de gênero no âmbito sexual. percepção do outro. Como se faz isso? Para início, é necessário, imprescindivelmente, um esforço próprio para conosco mesmo, é necessário aguçar os sentidos da Visão, da Audição, do Tato, do Olfato e do Paladar. Há os que enxergam mas não veem, os que ouvem mas não escutam, os que tocam, mas não sentem, os que cheiram, mas não distinguem essências eos que comem e não sentem sabor. É nessa esteira que construímos este tópico sobre a educação em relação aos haitianos, com um convite à reflexão sobre a imigração, pelo olhar de Abdelmalek Sayad (1998), "percebendo-o, tanto pela sociedade que o recebe como por aquela da qual advém”. Para isso, por conseguinte, é preciso, ainda que de forma breve, imergir em alguns aspectos da história e educação no Haiti.

Quem já teve a oportunidade de conversar com haitianos ${ }^{5}$ deve ter percebido, se teve tato, que, geralmente, são pessoas que têm um conhecimento relativamente consistente acerca da história do país, de política e, de certo modo, de línguas, além de demonstrar um profundo apreço e respeito pela vida escolar e pelas pessoas que estudam.

Essa forma de ser e de pensar não é por acaso, principalmente por pertencer a um país com uma história marcada por contrastes e por lutas grandiosas, afinal, com o despontar do século XIX, em seus primeiros anos, uma ilha do Caribe realizara um dos grandes feitos da história das Américas. Tornava-se a primeira república negra da humanidade. $\mathrm{O}$ ano de 1804 parece ter durado mais para os habitantes da ilha de Santo Domingo, tamanha fora a comemoração pelo grandioso feito. Naquele dia, o longo silêncio de dominação fora rompido e a lembrança da última batalha - de Vertière, ocorrida em 18 de novembro de 1803, em Okap, continuava viva na memória dos habitantes da pequena ilha que, agora, passava a chamar-se República do Haiti. Foi, também, a primeira vez na história que uma revolução de pessoas escravizadas saiu vitoriosa diante de seus algozes. E, como assinalou Robin Blackburn (2002), "o Haiti não foi o primeiro Estado americano independente, mas foi o primeiro a afirmar a liberdade civil de todos os habitantes" (p. 278-9).

No contexto dessa grande façanha, os principais símbolos da identidade haitiana começaram a ser construídos, como a exclusão da faixa branca da bandeira e a junção do azul e o vermelho, representando, respectivamente, a união entre o negro e o mulato. O nome Ayiti foi uma escolha em memória aos povos indígenas que viveram na ilha e o seu significado é, segundo o linguista haitiano, Michel DeGraff (2010), "terra de montanhas". $\mathrm{O}$ vodu, mesmo diante de tantas perseguições e tentativas de extermínio religioso permaneceu como marca de resistência (Hurbon, 1987) e manteve uma estreita ligação 
6 Para melhor compreensão sobre as desigualdades internas no Haiti, sugerimos os trabalhos de Rosa (2006) e Casimir (2012). com a língua da maioria, o Kreyòl Ayisyen (Rodrigues, 2008). Esses elementos, congregados, tornaram-se os mais importantes símbolos da identidade haitiana, no entanto, a língua do povo colonizador deixou sua marca.

Ao se tornarem independentes, o francês foi legalmente decretado, por Dessalines, a língua oficial da Ilha. Não obstante a isso, o crioulo continuou vivo, pulsante, nos quatro cantos do Haiti, o que levou, após incessantes lutas empreendidas por linguísticas e intelectuais, desde a década de 1930, na Constituição de 1987, a esperada oficialização do crioulo haitiano como língua oficial do Haiti. Ao lado do crioulo haitiano, a religião vodu - só reconhecida enquanto tal em 2003 - exerce um importante papel na história do Haiti e a própria formação sociocultural dos haitianos. Desde o processo revolucionário, o vodu foi determinante nos feitos históricos.

Tendo se tornado em Saint Domingue, um marrom, Boukman soube captar o momento e converter em favor de seus companheiros de condição social. Unificou os loas - espíritos - de diferentes cultos em um único panteão e de acordo com a história e a tradição oral, na noite de 14 de agosto de 1791, como houngan-sacerdote vodu -, juntamente com uma mambó - sacerdotisa vodu - realizou um ritual em Bwa Kayiman e selou um juramento com seus companheiros de eliminar os brancos e promover a libertação do povo. A partir desse momento, desencadeou o processo revolucionário com a queimada dos canaviais, destruição dos engenhos e retaliação sobre os blancs. (Cotinguiba, 2014, p. 77).

Assim, por muito tempo no Haiti ensinava-se maciçamente nas escolas a língua francesa, mas os haitianos continuavam falando o Kreyòl; pregava-se o catolicismo e o protestantismo, mas a prática de transcendência era o vodu. É nesse cenário sociocultural que se desenvolve o sistema educacional no Haiti.

As bases do ensino no país foram oficialmente fincadas pelos fundadores do Estado haitiano, embora tenham sido espelhadas no modelo trazido pelos colonos franceses no período da escravidão e reproduzidas após a independência. Assim, como assinala Joint (2008), "para acompanhar a evolução do sistema educacional do Haiti, é preciso ressaltar a lógica desigual desse sistema desde a sua criação" (p. 182). Essa lógica é que irá determinar, por exemplo, a separação, no âmbito escolar, das classes sociais. As poucas escolas nacionais que existiam, desde o início da instituição do sistema educacional, eram um privilégio $^{6}$ das classes de maior poder aquisitivo. Desse modo, a escola pública haitiana, nessa época, não era para todos (Joint, 2008). 
Porvolta da década de 1860, escolas católicas mantidas por congregações se instalaram no Haiti, para promover a formação de uma elite cristã. A entrada dessas instituições de ensino católicas, segundo Joint (2008), foi um chamariz para as famílias mais abastadas que alimentavam a crença na possibilidade de adquirir um ensino de excelência para os filhos nessas escolas congregacionais. Isso fez, por um tempo, com que as crianças provenientes de classes populares frequentassem as escolas mantidas pelo Estado. As instituições educacionais católicas tiveram grande influência na educação do Haiti, inclusive como coadjuvante no aumento da separação entre crianças pobres e ricas. É certo que houve um momento, mais especificamente na década de 1970, que as escolas católicas, em decorrência do aumento da demanda escolar, foram obrigadas a dividir o espaço de suas salas de aula entre alunos pobres e ricos.

Para perpetuar o princípio da distinção e da separação de classes, as crianças oriundas de famílias abastadas abandonaram progressivamente as escolas católicas congregacionais, aumentando a lista de escolas internacionais. O sistema educacional haitiano permanece em sua totalidade, ainda hoje, em conformidade com o que tinha como base, quando de suas primeiras implantações; ou seja, concretiza o objetivo de formar as elites separadas das massas ou das classes populares pobres (Joint, 2008, p. 184, grifo nosso).

A afirmação de Joint ratifica o papel preponderante da Igreja Católica na educação haitiana, desde o seu início como vedete na construção das desigualdades no país. Com o tempo, especialmente com a entrada de novas instituições educacionais internacionais no Haiti, o poder da Igreja Católica diminuiu sobremaneira. Isso ocorre, contudo, em relação à quantidade de escolas e não da perspectiva qualitativa, visto que,

Segundo análise da Fundação Haitiana das Escolas Privadas (FONHEP), em 1996, a igreja católica ocupava-se somente de $24 \%$ das escolas privadas do país, enquanto as escolas protestantes representavam $35 \%$ do total e as escolas privadas independentes (não religiosas), 29\%. Entretanto sob o ponto de vista qualitativo, as escolas católicas congregacionais continuavam a ter um papel determinante na organização e na orientação do sistema educativo haitiano. Elas estão entre as escolas mais bem equipadas e mais organizadas do país (Idem).

Há, no Haiti, as escolas privadas (religiosas ou não) que, em geral, têm um preço elevado, e as escolas públicas, os chamados Liceus. Mesmo sendo mantido pelo Estado, os 
estabelecimentos públicos cobram uma taxa anual, o que, muitas vezes, dificulta a permanência de muitas crianças na escola.

Outro fator que serviu de mote para uma das muitas tentativas de mudança no sistema educacional haitiano, como já assinalamos anteriormente, foi a oficialização do Kreyòl, em 1987. A língua falada desde antes da independência pelos haitianos poderia, a partir de então, ser estudada nas escolas. Dessa forma, houve modificações na maioria das escolas do país, qual seja, o Kreyòl passou ser a principal língua ensinada nos primeiros anos do ensino fundamental e o "francês oscilaria, conforme a escola, entre língua suplementar de instrução e segunda língua de alfabetização" (Nascimento e Thomaz, 2010, p. 44). Foi uma iniciativa importante porque representou a possibilidade de ascender grupos tradicionalmente marginalizados, por todos os motivos que já demonstramos anteriormente, em relação à formatação e desenvolvimento da escolarização formal no Haiti. Por motivos diversos, entretanto, a reforma educacional no país ainda está distante de atingir seus objetivos.

O ensino fundamental constitui-se de nove anos letivos, divididos em três ciclos, respectivamente de quatro, dois e três anos. Já o nível secundário, similar ao nível médio no Brasil, compreende quatro anos, levando à obtenção de um diploma secundário, chamado Segundo Bacharelado ou Bac II. A obtenção desse certificado é o que dará acesso à universidade, que também envolve um exame de admissão. A despeito da reforma educacional, essa configuração ainda não se universalizou e algumas escolas seguem operando com base na estrutura clássica do modelo francês tradicional, também de 13 anos, mas divididos em seis anos básicos, quatro anos ginasiais e três anos de escola secundária. No caso do Bac II, ao seu término, o estudante precisa realizar uma prova e obter êxito para, assim, receber o diploma.

Nossa reflexão se dá, neste momento, a partir de um diálogo teórico com autores que escreveram sobre a educação no Haiti. Temos consciência da nossa limitação pelo fato de ainda não termos realizado observação in loco no Haiti e, com isso, conhecer pessoalmente parte do sistema político e burocrático e da dinâmica escolar no país, algo que vislumbramos num horizonte próximo. A despeito disso, entendemos que, de uma maneira sucinta, apontamos os principais aspectos sobre a maneira como o sistema educacional haitiano se estruturou e, com isso, oferecemos um contributo para que as instituições brasileiras que estão recebendo haitianos candidatos a estudantes possam, assim, ter uma noção comparativa e qualitativa do sistema escolar haitiano frente às demandas do ambiente escolar brasileiro. 
7 Por residirmos em Porto Velho, esta cidade é o locus por excelência de nossa pesquisa, contudo, dada a presença dos haitianos em diferentes regiões do território brasileiro, deslocarmo-nos por diferentes locais, tentando realizar uma pesquisa de campo multilocal - "ethnography multi-sited" (Marcus, 1995) -, dadas as ressalvas. Em outro artigo (Cotinguiba y Pimentel, 2014b), relatamos mais detidamente outros aspectos da nossa pesquisa de campo.

8 Este jovem, nosso amigo, ao retornar ao Haiti para visitar sua família, faleceu repentinamente. À sua memória.

\section{ELEMENTOS DE UMA PESQUISA DE CAMPO MULTILOCAL ${ }^{7}$}

Desde o início de nossa entrada em campo, em 2011, percebemos que nos desdobramentos da imigração haitiana para o Brasil, nossa pesquisa seria o passaporte que nos levaria a outras cidades o que, inevitavelmente aconteceu. Somadas as viagens que nós realizamos, o total de cidades já chega a 24 - incluindo Porto Velho -, das quais duas são em outros países, Cobija, na Bolívia e Iñapari, no Peru. À região de tríplice fronteira - Brasil-Bolívia-Peru - fomos quatro vezes, sendo a primeira em janeiro de 2012 e a última em janeiro de 2014 e, no momento, preparamos uma quinta viagem de retorno, para observações pois, desde abril de 2014 o local que era mantido como "abrigo" pela parceria governo do Acre e governo federal, em Brasileia, Acre, foi desativado e as atividades foram transferidas para a capital acreana, Rio Branco.

Essa necessidade se deveu à dinâmica migratória haitiana que, como insiste um colega antropólogo, é "uma mobilidade de pessoas" - professor doutor Joseph Handerson (2015), da Universidade Federal do Amapá, em sua tese de doutoramento no Museu Nacional, da Universidade Federal do Rio de Janeiro. Essa mobilidade significa que não se trata de uma migração nos moldes das teorias clássicas migratórias, aquelas em que os migrantes ou imigrantes se dirigiam a um determinado lugar e nele se estabeleciam, mas é um processo migratório dinâmico dadas as exceções. É nesse sentido, que Handerson afirma que a "mobilidade se revela constitutiva do mundo social e dos horizontes de possibilidades dos haitianos" (p. 371).

O autor ainda mostra como a vinda dos haitianos ao Brasil está articulada com a Guiana Francesa. A fala de um jovem, em resposta a uma pergunta a um ouvinte em uma palestra, em Porto Velho (2014), reflete o que isso quer dizer e, também, o sentimento de muitos outros que nos revelaram a mesma coisa. "Você pretende ficar no Brasil? Pergunta. Resposta - "Bem, essa é uma pergunta difícil e, como nós haitianos dizemos, sèl Dye ki konen, isto é, só Deus que sabe. Meu objetivo era a Guiana Francesa, mas fiquei aqui no Brasil. Aqui estou e vou ficar até o dia que tiver trabalho e, quando não tiver, vou para onde tem, pode ser qualquer lugar ${ }^{8}$.

Isso demonstra uma relevância em relação a essa imigração, a característica de que estamos diante de um movimento migratório que, como já dissemos, é diferenciado daqueles do passado. Como já apontaram Ninna Glick-Schiller e Georges Fouron (2001), os haitianos levaram as autoridades políticas e os pesquisadores a encontrarem uma nova definição conceitual para o fenômeno da migração, a 'migração transnacional', caracterizada por uma mobilidade por diferentes espaços nacionais e estruturada a partir de um sistema de relações 
de parentesco no qual a rede familiar exerce papel central no processo de inserção social (Audebert, 2004; Nieto, 2014), fundamentado numa lógica de obrigações morais que, como temos observado, insere-se naquilo que foi descrito por Marcel Mauss (2003) como um "sistema de prestações totais", em que os indivíduos se veem obrigados a prestarem auxílio mútuo que, no caso dos haitianos, a base na qual tudo radica são os laços de consanguinidade.

Assim, para melhor compreendermos, tanto a dinâmica dessa mobilidade quanto a sua lógica de organização pela qual os indivíduos se inserem e traçam suas estratégias, o caminho mais curto, paradoxalmente, era percorrer uma longa distância, isto é, viajar por diferentes lugares, visitar instituições, conversar com brasileiros responsáveis por alguma atividade de apoio aos haitianos, visitar, entrevistar e conversar com haitianos em suas associações, locais de trabalho, locais de estudo, casas, ruas, em ônibus, igrejas etc. Certamente, uma vivência de quase quatro anos, o contato com tantas pessoas e o que vimos, ouvimos e registramos não poderia ser aqui exposto e, por isso, a opção que fizemos em optar por um recorte sobre um aspecto apenas, dentre tantos, a questão da educação. Das 24 cidades que estivemos com a finalidade exclusiva da pesquisa, escolhemos algumas para relatarmos alguns pontos para, mais adiante, refletirmos sobre os desafios que os haitianos têm encontrado em seu caminho para a inserção no ambiente escolar.

\section{CUIABÁ, MATO GROSSO.}

Nossa viagem à cidade de Cuiabá ocorreu no primeiro trimestre de 2014. Nesta viagem tivemos, como objetivos, realizar um mapeamento das instituições envolvidas no processo de inserção dos haitianos na cidade, visitas aos haitianos que tínhamos contato por meio direto, desde sua passagem por Porto Velho ou por intermédio de parentes que nos havia colocado em contato e, também, conhecer a Associação haitiana que estava em formação e ouvir seus pontos de vista. Todas as nossas expectativas foram atendidas.

Em relação à educação, que é o foco central deste artigo, encontramos alguns projetos em curso. Das instituições visitadas, na Universidade Federal de Mato Grosso, UFMT, conhecemos uma equipe multidisciplinar do curso de Saúde Coletiva, que estava construindo um projeto de pesquisa para acompanhamento dos haitianos em diferentes bairros, assim como previam a formação de um curso de extensão para proporcionar a esses imigrantes informações e acesso a direitos sociais no campo da saúde. À época participamos de uma 'roda de conversa' sobre o tema com professores e estudantes. 
Outra instituição visitada foi o Serviço Nacional de Aprendizagem Industrial, o SENAI. Nesta instituição, os cursos estavam voltados para a área da construção civil, para pedreiros, assentar cerâmica, dentre outros. Os cursos eram realizados, geralmente, com outras instituições parceiras, ministrados por profissionais contratados temporariamente apenas para a duração da carga horária. Visitamos uma instituição que contava com a parceria com o SENAI e, na ocasião havia duas turmas em andamento, uma sobre assentamento de cerâmica e outra sobre construção em alvenaria.

O SPM atuava, naquele momento, como um local de referência para muitos dos que chegavam à cidade, orientação sobre direitos trabalhistas, alojamento, alimentação e os primeiros passos no aprendizado da língua portuguesa. A sede do SPM se tornara um local de destino de muitos haitianos, para muitos dos que chegavam à cidade em busca de um abrigo quanto para os residentes que, periodicamente, visitavam o local em busca de informações de seus interesses, assim como em busca de encontrar amigos ou parentes. Chamou-nos a atenção o caso de um rapaz que havia estudado e concluído o curso de medicina na República Dominicana e portava toda a documentação e, no entanto, não podia exercer sua profissão devido aos entraves burocráticos. Não tivemos notícias sobre o desfecho de sua busca.

No Conselho Estadual de Educação, estivemos a convite de sua diretoria para uma mesa de discussão com representantes de diferentes setores do governo e da Sociedade Civil e o que estava em curso, naquele momento, era um projeto sobre a criação de um currículo diferenciado em uma escola da rede pública estatal para a inserção dos haitianos, além das questões burocráticas sobre a convalidação de documentos escolares.

Na Associação haitiana, quando de nossa reunião com seus membros do comitê representativo, dentre as diferentes demandas que apresentavam e discutiam, a educação figurava como uma das principais, para todos os níveis, tanto a preocupação com as crianças que estavam chegando à cidade quanto aos que desejavam estudar no rede pública de ensino, a convalidação de documentos e os que desejavam ingressar na universidade e não encontravam explicações ou auxílio para compreenderem a lógica do sistema educacional brasileiro.

A realidade dos haitianos em Cuiabá, do ponto de vista de inserção no ambiente escolar não era, significativamente, diferente do que conhecíamos até então em Porto Velho. As mesmas dificuldades, os mesmos entraves burocráticos. A expectativa da diretoria do Conselho, especialmente de seu vice-presidente, era a de que por meio de parcerias, como por exemplo, o movimento negro de Cuiabá, houvesse um movimento no sentido de cobrar da Secretaria Estadual de 
9 COTINGUIBA, Geraldo Castro; PIMENTEL, Marília Lima \& NOVAES, Maria de Lourdes (Org.). Língua portuguesa para haitianos. $1^{\mathrm{a}}$ ed. Florianópolis: SESI. Departamento Regional de Santa Catarina, 2014. $219 \mathrm{p}$.

10 Agradecemos à antropóloga Dra. Margarita pelo convite. Os custos dessa viagem foram pagos pela Univates, responsável pela nossa ida à cidade.
Educação a inserção dos haitianos no ambiente escolar. O mesmo era a expectativa da equipe que conversamos, do curso de Saúde Coletiva da UFMT, realizar um trabalho em prol dessa inserção.

\section{PORTO ALEGRE E DUAS CIDADES DO VALE DO TAQUARI, RIO GRANDE DO SUL}

Numa viagem a Porto Alegre, a convite do governo do estado, por meio de sua Secretaria de Justiça, o objetivo central foi oferecer um minicurso para pesquisadores e pessoas que trabalham com o atendimento a imigrantes em Porto Alegre, promovido pela Secretaria de Justiça e Direitos Humanos do Rio Grande do Sul e do GAIRE da Universidade Federal do Rio Grande do Sul - UFRGS. Esse minicurso teve como objetivo uma breve formação de uma equipe que estava, naquele momento, envolvida com questões relativas aos haitianos em defesa de seus direitos sociais. Na ocasião tivemos, ainda, a oportunidade de participarmos de uma discussão com um grupo de professores e militantes de movimentos sociais em uma escola da cidade e, também, apresentar resultados de nossas pesquisas no III Seminário de Mobilidade Humana do Rio Grande do Sul.

Finalizadas as nossas atividades em Porto Alegre, atendemos a um outro convite para realizarmos um workshop em Lajeado, no Rio Grande do Sul. Além de Lajeado, visitamos a cidade de Encantado, para conhecermos a equipe que oferecia o curso de português para haitianos e dominicanos. A equipe, formada por uma voluntária, professora de Língua Portuguesa, além do apoio do SPM, com um assistente. O fato de o padre da paróquia ser um haitiano facilitava a comunicação do grupo de voluntários com os imigrantes haitianos. Trocamos informações e disponibilizamos o livro sobre o ensino da língua portuguesa para os haitianos, criado por nossa equipe a partir de nossa vivência em Porto Velho9. Já em Lajeado ${ }^{10}$, a nossa permanência foi com o objetivo de participarmos de um encontro com professores e estudantes de uma universidade da rede privada, além de servidores municipais. A partir da demanda local - inserção dos haitianos no ambiente educacional - conforme nos foi relatado, conduzimos nossa discussão sobre a importância de partir de projetos que contemplassem, acima de tudo, as reais necessidades dos indivíduos, de modo que os envolvidos no projeto previamente se envolvessem em projetos de pesquisa ou extensão universitária a fim de conhecer a realidade dos haitianos para, em seguida, apresentar propostas que pudessem, dessa forma, atender suas expectativas. Segundo um jovem haitiano que participou do evento - Simon, estudante de Relações Internacionais na universidade -, havia na região cerca de 
11 Universidade Federal da Fronteira Sul - UFFS. Agradecemos o convite e o Apoio da coordenadora do LIFE e da equipe do PROHAITI, na pessoa da professora Sandra Bordignon. No entanto, nós dois já estivemos por duas vezes em Florianópolis, a convite da Diretoria de Educação do Serviço Social da Indústria, SESI, e, por uma vez em Balneário Camboriú, Itajaí, Navegantes e Balneário Piçarras. Nesta última cidade dormimos na casa de um amigo haitiano e sua família.
2 mil haitianos, com diversas demandas, como questões documentais em relação à embaixada haitiana e, também, sobre o desejo e a necessidade de inserção no ambiente escolar. Não havia, contudo, nenhum projeto de inserção dos haitianos no ambiente escolar da cidade e da região e, pelo que pudemos perceber e, com base nos depoimentos dos participantes do evento, não havia uma discussão em curso sobre o tema. A nossa ida à cidade era o início daquilo. Havia, contudo, iniciativas esporádicas e individuais, como o caso de Simon, que procurou escolas e fez os exames para a conclusão do Ensino Médio.

\section{ALGUMAS AÇÕES EM CURSO: SANTA CATARINA ${ }^{11}$ E PARANÁ}

Em Chapecó, há uma ação pontual com relação à inclusão dos haitianos no ensino superior, trata-se do projeto PROHAITI da Universidade Federal da Fronteira Sul - UFFS. O PROHAITI tem a intensão de contribuir, por meio de vagas suplementares, para integrar os imigrantes haitianos à sociedade local e nacional, por meio do acesso aos cursos de graduação da UFFS. O programa teve início em 2013 e, no início, ofertou oportunidades de formação superior, exclusivamente, a cidadãos haitianos residentes no município de Chapecó e região. De acordo com o Programa, as vagas destinadas aos haitianos são ofertadas por meio de processo seletivo especial e o aluno que ingressar através do processo será matriculado como aluno regular.

O primeiro processo seletivo foi realizado em março de 2014 por meio de um edital específico para este fim, prevendo acesso à educação superior da UFFS para estudantes haitianos - PROHAITI com o total de 35 inscrições. Após os trâmites normais do processo, inscrição, provas, resultado foram realizadas as matriculas de 27 alunos nos cursos de Administração, Ciências Sociais, Enfermagem, Engenharia Ambiental, História, Letras Português e Espanhol, Matemática e Pedagogia. Em julho de 2014 foi realizado outro processo seletivo, com 33 inscrições. Desse total de inscritos, 12 haitianos foram matriculados nos cursos de Administração, Agronomia, Ciência da Computação, História, Letras Português e Espanhol, Pedagogia e Geografia. Até novembro de 2014 havia 39 alunos haitianos matriculados na Universidade Federal da Fronteira Sul, no âmbito do programa PROHAITI. Em nossa visita a Chapecó conhecemos outras iniciativas que ajudam na inserção social educacional dos haitianos como um curso e extensão de ensino de língua portuguesa realizado por um grupo de professores e alunos da Universidade Federal da Fronteira Sul, com carga horária de 30 horas. 
12 Shellot Pubien é estudante de Cinema e Audiovisual. Com sua autorização publicamos seu nome. Foi Secretário da Associação Haitianos Cariocas, na cidade do Rio de Janeiro.
Ainda no oeste catarinense, visitamos o munícipio de Nova Erechim, com cerca de 4900 habitantes, localizado a $44 \mathrm{~km}$ de Chapecó. Nessa cidade, um grupo de voluntários elaborou um projeto denominado "Programa conhecimento/cultura - Brasil/Haiti", que teve como objetivo oportunizar o acolhimento e a comunicação dos cidadãos haitianos residentes no município. $\mathrm{O}$ projeto existe até hoje e já passaram pelas aulas de português aproximadamente 50 haitianos.

Há algumas modalidades ou programas de inserção de estudantes haitianos no ambiente escolar do ensino superior brasileiro, como os convênios de algumas universidades para intercâmbio, que os estudantes vêm para o Brasil, estudam e devem, geralmente, ao final do curso, retornar ao Haiti. Dentre as universidades que aderiram a esse projeto, temos conhecimento da presença de grupos de estudantes haitianos na Universidade Estadual de Campinas, a Unicamp, assim como encontramos pessoalmente com estudantes haitianos em Curitiba, da Universidade Federal do Paraná, UFPR e em Florianópolis, pela Universidade Federal de Santa Catarina, a UFSC.

Em relação ao Paraná, um caso mereceu nossa atenção e destaque. É o de um jovem ${ }^{12}$ que desde meados de 2014 temos mantido contato. Primeiramente, quando ele morava na cidade do Rio de Janeiro e nos procurou via redes sociais - facebook e whatsapp- para auxiliá-lo no processo de abertura de uma associação dos haitianos naquela cidade. Por termos assessorado aos haitianos em Porto Velho na formação de uma associação e outros em Balneário Camboriú e Navegantes, enviamos todos os procedimentos burocráticos e a associação foi formada. A partir disso nosso contato não mais se encerrou.

Em dezembro de 2014, a Universidade Federal da Integração Latino-Americana, UNILA, lançou o Edital no 004/2014 que, em seu resumo "Regulamenta o processo de seleção do Programa Especial de Acesso à Educação Superior da UNILA para estudantes haitianos - PróHAITI, para ingresso no primeiro semestre letivo de 2015, na Universidade Federal da Integração Latino-Americana" (p. 1). No total foram ofertadas 29 vagas, sendo 22 para o bacharelado e 7 para a licenciatura, contemplando diversas áreas, sendo apenas uma para cada curso.

Pela relação de amizade que desenvolvemos com Pubien, quando ele tomou conhecimento do edital procurou-nos para pedir ajuda quanto ao processo. Ele havia providenciado todos os documentos, redigiu carta de apresentação e outras que o edital demandava. Enviou-nos todas para que pudéssemos verificar se toda documentação estava de acordo. Auxiliamos em todo o processo e nos colocamos como referências para contato em seu currículo e a documentação foi submetida para avaliação. Quando o resultado foi publicado tomamos conhecimento de que 
ele havia sido um dos aprovados para estudar e, com isso, teria que se mudar da cidade do Rio de Janeiro para Foz do Iguaçu. Para ilustrarmos melhor esse caso, consideramos que o melhor que poderia ser feito, ou melhor, dito, era pelo próprio sujeito e, por isso, pedimos a ele para redigir um relato sobre esse acontecimento. Seu depoimento é o que segue, da maneira como foi escrita por ele.

Para mim, e para a maioria dos haitianos, a educação é a chave do sucesso. Chegando no Brasil, não é sempre fácil conseguir um emprego bom, que sejamos formados ou não. Pela necessidade de se manter, somos obrigados de aceitar qualquer tipo de trabalho. Abastecido pela vontade de mudar de condição de vida, como muitos outros haitianos, eu decidi de esquecer minhas formações anteriores e procurei a fazer um estudo avaliado pelo mercado de trabalho do Brasil. E rodei a cidade do Rio de Janeiro inteiro, atrás de oportunidade de estudar. Finalmente, consegui passar o Vestibular numa universidade na cidade; fiquei surpreendido do fato que entre a mensalidade da faculdade e o meu salário a diferencia era pouco, pouquíssimo. E, atrapalhado pela língua portuguesa, não é fácil para um haitiano conseguir umavaganuma universidadepública do Brasil por meio de concurso. Desesperado, mas paciente e sobretudo perseverante, não parei de buscar oportunidade de estudar. Assim, em Janeiro, participei num programa de bolsas para estrangeiros de uma faculdade federal do Brasil, e consegui. Para mim, é uma graça que caiu do céu. Eu confesso que não é fácil, psicologicamente e economicamente. Pois, apesar que tenho uma filha para sustentar, eu tinha que pedir contas após 18 meses de trabalho numa empresa no Rio de Janeiro, para poder aproveitar dessa chance única e tocar em frente atrás do meu sonho. Pois, apesar de tudo, estudante em Cinema e Audiovisual, eu vejo a luz no final do túnel, e isso é um sinal de vitória (Pubien, via e-mail, Foz do Iguaçu, 2015).

Esses casos, da UNILA e da UFFS, demonstram que alguns caminhos estão sendo abertos e, no decorrer desse processo migratório vislumbramos a possibilidade de novas oportunidades serem colocadas em prática.

\section{RELATO DE CASO EM PORTO VELHO}

Como já indicado anteriormente, Porto Velho é a cidade onde vivemos e onde nos inserimos nesta pesquisa. Situada no extremo norte do estado e sendo a capital de 
13 Do ponto de vista jurídico, para ter validade os documentos precisam ser traduzidos por um tradutor juramentado.
14 Este estudante será o primeiro haitiano a graduar-se em Porto Velho, em Gestão de Recursos Humanos, com um estudo sobre a contratação de haitianos pelo consórcio responsável pela construção da Hidrelétrica Santo Antônio.
Rondônia, a cidade tem cerca de 500 mil habitantes, de acordo com estimativas do Instituto Brasileiro de Geografia e Estatística, o IBGE. Pela sua localização é uma cidade que está na rota migratória dos haitianos que entram pelo estado do Acre, cuja discussão sobre essa rota, as estratégias e seus desdobramentos já apontamos em outros trabalhos (Cotinguiba, 2014; Cotinguiba e Pimentel, 2014a; 2014b).

Tomaremos dois casos para análise sobre o processo de convalidação de certificado de equivalência de Ensino Médio. O relato que segue é com base no que acompanhamos ao longo de alguns meses, desde as primeiras tentativas de convalidação, a entrada dos haitianos em uma faculdade privada, a burocracia do Conselho de Educação, os diálogos com a Embaixada haitiana no Brasil, a intermediação com a Embaixada brasileira no Haiti e, por fim, a convalidação.

No início de 2014, dois rapazes nos procuraram para que os ajudássemos no processo de convalidação de seus certificados de Retho e Philo - equivalente à conclusão do ensino médio no Brasil. Por meio de um amigo, professor da Unir, os documentos foram traduzidos ${ }^{13}$ e, assim, seguiram para avaliação do Conselho. A necessidade desses dois rapazes era pelo fato de ambos já se encontrarem matriculados em cursos a distância em uma faculdade, que lhes exigia a convalidação, sob pena de terem o estudo interrompido caso os documentos não fossem entregues em tempo hábil.

Após as diligências em busca de uma solução, os documentos foram organizados em forma de um pequeno dossiê e dado entrada no Conselho. Dadas as alegações de 'insistentes' cobranças realizadas pela faculdade, os rapazes pediram, mais uma vez, a nossa ajuda. Procuramos o Conselho e marcamos uma reunião com membros da equipe responsável pelos documentos dos dois haitianos. Essa reunião aconteceu no mês de agosto daquele ano, já com o ano letivo em seu segundo período. Cerca de dois meses depois um dos jovens foi obrigado a trancar a matrícula e encerrar, provisoriamente, seus estudos, enquanto o outro conseguiu uma transferência para outra faculdade, na modalidade presencial ${ }^{14}$, com a promessa de legalizar os documentos. Na reunião, fomos informados que o Conselho não poderia convalidar os documentos porque não dispunha de uma 'tabela de equivalência' da educação no Haiti, para comparação com o Brasil. Disseram-nos que seria necessário terem um documento oficial constatando que aqueles documentos apresentados pelos rapazes eram equivalentes ao Ensino Médio brasileiro. Dado o nosso conhecimento junto à Embaixada haitiana, em Brasília, fizemos contato com o Cônsul e enviamos um $e$-mail para o Embaixador. Cerca de uma semana depois recebemos uma declaração assinada pelo Embaixador e carimbada em relevo atestando que os haitianos haviam concluído o Ensino Médio no Haiti. Ao ser entregue no Conselho 
Estadual de Educação, o argumento foi o de que não poderiam aceitá-lo, pois precisavam que os certificados constassem o carimbo da Embaixada brasileira no Haiti e o selo do Cônsul brasileiro. Alegaram, ainda, a possibilidade de solicitarem a lei de educação do Haiti, traduzida.

Nesse ínterim, um dos rapazes estava de férias do trabalho e viajou para o Haiti e levou consigo os documentos para serem consularizados na Embaixada brasileira, além de uma carta de apresentação que fizemos para ser entregue ao Cônsul brasileiro. Ao retornar do Haiti o rapaz, então, procurou o Conselho de Educação e, mais uma vez, entregou os documentos. Quase um ano após a convalidação se realizou e, em fevereiro de 2015 os documentos foram, finalmente, convalidados.

A partir desse caso - que pode ser considerado duplo -, podemos perceber a dificuldade que os haitianos enfrentam no Brasil para estudarem. Também, o que se denota é a ausência de uma política na qual as instituições responsáveis pelos trâmites burocráticos possam se basear. Sabemos que os Conselhos Estaduais de Educação têm autonomia, mas diante do que vimos, com a ausência de um documento de equivalência sobre o quadro de educação do país, isso amplia a dificuldade. Se a imigração haitiana para o Brasil é uma prática corrente nos últimos 5 anos, cabe perguntarmos: por que o Estado brasileiro ainda não se mobilizou, por meio de seu Ministério de Relações Exteriores, a dialogar com o Estado haitiano para a disponibilização de um documento dessa natureza? $\mathrm{Na}$ mesma linha, a pergunta se estende ao Estado haitiano. Cabe, portanto, uma reflexão sobre os desdobramentos dessa questão.

\section{REFLEXÕES SOBRE OS DESAFIOS DIANTE DAS LIMITAÇÕES BUROCRÁTICAS}

O foco de nossa discussão é sobre as limitações encontradas pelos dyaspora - aqueles que têm permanência determinada pelo "Visto por ajuda humanitária", com base na Resolução 97/2012 do Conselho de Imigração, o CNIg. Os desafios que os haitianos encontram no Brasil, no campo da educação, apresenta um quadro flagrante da ausência de uma política de imigração e, neste caso, de um despreparo quanto a esse fluxo migratório. E o despreparo não se deve, ao que supomos, por falta de conhecimento da imigração haitiana ou mesmo do 'perfil migratório' desse povo para o Brasil, uma vez que, quando essa imigração começou, as tropas militares brasileiras já se encontravam no Haiti há 6 anos, comandando as tropas militares a serviço das Nações Unidas - ONU -, sob o pretexto de "estabilização" da paz no Haiti.

Esse seria um tempo suficiente para se conhecer razoavelmente aspectos essenciais sobre uma sociedade 
de cerca de 9 milhões em um território de 27,7 mil $\mathrm{Km}^{2}$. A isso, soma-se a presença de uma equipe consular brasileira no país. De maneira didática, elencaremos as principais dificuldades educacionais encontradas pelos haitianos no Brasil que, de fato, começam ainda no Haiti. De acordo com os nossos interlocutores, a cada dia vão à embaixada brasileira no Haiti cerca de 200 pessoas com o objetivo de obter um visto. Como já demonstrado em outro trabalho (Cotinguiba, 2014, p. 93), a limitação de pessoal na embaixada brasileira é um empecilho, uma vez que menos de duas dezenas de pessoas por dia conseguem ser atendidas.

\section{O ENSINO FUNDAMENTAL E MÉDIO, OS DE- SAFIOS PARA ESTUDAR NA UNIVERSIDADE}

Tomaremos como primeira adversidade aquela encontrada pelos haitianos que concluíram os estudos préuniversitários no Haiti, equivalentes no Brasil ao Ensino Médio. No Haiti, esse nível escolar é composto por 4 anos de estudo e o estudante que o conclui recebe, geralmente, dois certificados (diplôme) - dependendo do caso, o estudante pode optar em receber apenas um, que tem a mesma equivalência. Esses certificados são identificados pelos estudos realizados, indicado por Retho ou Philo, seguido de outro, a Table Réléve, equivalente ao histórico escolar.

Para o candidato que almeja uma vaga em uma universidade ou faculdade brasileira, privada ou estatal, o desafio é a legalização jurídica dos documentos estudantis. Os casos que temos acompanhado em Porto Velho e os que tomamos conhecimento em outras cidades, como em Cuiabá e em Curitiba, no ato da realização da matrícula na instituição de ensino superior - IES -, são exigidos do estudante os seguintes documentos: certificado e histórico traduzidos por um tradutor juramentado, um documento de convalidação do certificado feita por um Conselho de Educação. Curiosamente não encontramos, em nenhum lugar, a exigência da proficiência na língua portuguesa - o que não queremos dizer que isso não exista. Essa limitação não se encerra aqui. Por ser um dyaspora, geralmente faz parte do grupo que entrou no Brasil via rota migratória que já descrevemos em outro trabalho (Cotinguiba e Pimentel, 2014a). O que o dyaspora não sabe é que as IES exigem que o certificado contenha um selo de consularização, que se obtém no Consulado brasileiro no Haiti, mediante o pagamento de 20 dólares estadunidenses (US\$20,00). Por já se encontrar no Brasil, esse dyaspora precisa, assim, enviar seus documentos de volta ao Haiti para que, dessa forma, algum membro da família possa ir até o Consulado brasileiro para autenticar o documento. 
Essa adversidade poderia ser superada a partir de algumas formas. Primeiramente, se houvesse interesse por parte do governo brasileiro, poderia ser divulgada a notícia no Haiti sobre os procedimentos a esse respeito. $\mathrm{O}$ argumento negativo a isso é que poderia soar como um convite ou incentivo à emigração. A segunda maneira poderia ser por meio do CNIg, de forma que pudesse autenticar esse documento, do mesmo jeito que o Consulado o faz no Haiti. Talvez o argumento contrário seja o de que o CNIg não é uma instância deliberativa federal. A terceira opção poderia ser um acordo entre os governos brasileiros e haitiano, de maneira a reconhecer o documento no Brasil por meio de alguma instância, seja por meio da Embaixada haitiana ou por meio do Ministério da Justiça brasileiro. Isso evitaria os altos custos que muitos dyaspora têm ao terem de reenviar os documentos para o Haiti, os trâmites no país, os pagamentos das taxas e o reenvio para o Brasil. Isso não é idealismo, é possível de ser realizado, falta interesse e empenho políticos.

A convalidação de um diploma universitário no Brasil constitui-se uma saga, independente da nacionalidade da pessoa, mesmo para os brasileiros que estudam em outro país. Para se convalidar um diploma universitário no Brasil é necessário que o candidato esteja de posse de todos os documentos, isto é, diploma, histórico escolar e as ementas de todas as disciplinas cursadas. De posse desses documentos, o passo seguinte é providenciar a tradução de todas as páginas dos documentos, somente aceitas por meio de um tradutor juramentado. Os custos podem variar e depende de quanto o tradutor cobra por cada página traduzida. Uma página para traduzir pode variar entre $\mathrm{R} \$$ 30,00 a $\mathrm{R} \$ 100,00$, dependendo da cidade onde a pessoa se encontra. $\mathrm{O}$ total de páginas de um curso universitário pode variar e a média fica em torno de 50 . Além disso, as universidades brasileiras demoram muito tempo para fazer a convalidação, ou seja, o processo é muito moroso, pode demorar anos.

Para aqueles que iniciaram os estudos universitários no Haiti, no caso dos dyaspora, não temos conhecimento de que algum tenha conseguido prosseguir os estudos no mesmo curso no Brasil. O procedimento que temos encontrado é o de que o candidato deve fazer o vestibular e começar como novo estudante e, para isso, deve se submeter às mesmas regras antes descritas para quem tem o equivalente ao Ensino Médio brasileiro.

Há uma heterogeneidade sociológica, se assim podemos dizer, entre os haitianos. Como já apontamos em outro trabalho (Cotinguiba e Pimentel, 2012), essa heterogeneidade abrange diversos aspectos, como língua, origem nacional, classe social etc. além, é claro, dos níveis escolares, que vai do universitário ao que não teve acesso à escolarização. Nesse contexto, adultos, crianças e 
adolescentes, ao se estabelecerem - no caso de Porto Velho - e buscarem a inserção no meio escolar encontram suas barreiras. Por uma questão didática, escolhemos relatar esses aspectos pelas categorias acima mencionadas.

Há duas dificuldades encontradas pelos haitianos nesse quesito, não necessariamente na ordem que colocamos A primeira se dá pelo conflito, do ponto de vista compreensivo - para entenderem como funciona a lógica burocrática da escola estatal brasileira. A segunda é a barreira imposta pela limitação da língua. A maior dificuldade é encontrada pelos adultos, conforme relataremos abaixo.

Por ser uma população heterogênea, os dyaspora adultos apresentam um quadro variado de escolarização, com o equivalente ao Ensino Fundamental brasileiro completo e incompleto e, da mesma forma, o Ensino Médio. Para os que não concluíram o Ensino Médio, a barreira se dá perante a Secretaria Estadual de Educação que, no caso de Porto Velho, não tem uma diretriz de como avaliar os documentos para que o candidato possa prosseguir os estudos.

A presença de crianças não foi um fato recorrente registrado no início da migração, é parte do desdobramento de um processo mais amplo, especialmente respaldado pelo direito, uma vez que, de acordo com a Constituição Federal Brasileira de 1988, a família é inseparável, de acordo com a prescrição constitucional. O imigrante residente em solo brasileiro, uma vez gozando do direito ao visto de permanência, tem por direito requerer a reunião familiar e, na perspectiva brasileira, a família compreende marido, esposa e filhos e, dadas as proporções, os pais dos cônjuges, quando viúvos, uma vez que se comprove o grau de dependência dos pais do casal em relação aos filhos. No caso da imigração haitiana, o que temos conhecimento são os casos de reunião familiar do marido ou da esposa e filhos, desconhecemos casos de pais que conseguiram vistos para migrar para o Brasil nessa categoria.

Um dos diversos desafios encontrados pelos haitianos no Brasil é a inserção de seus filhos no sistema educacional brasileiro. A principal barreira é a língua. Numa escola, em Porto Velho, acompanhamos a saga de um grupo de crianças e pais que buscaram a nossa ajuda para realização das matrículas em escolas da rede estatal de ensino. Antes, porém, tivemos de acompanhá-los por três escolas para saber qual poderia realizar um exame de avaliação para as crianças e adolescentes para saber o nível de conhecimentos disciplinares escolares corresponde a cada ano do ensino fundamental, visto que as crianças portavam apenas uma caderneta, uma espécie de boletim escolar, com notas da série que estudaram no Haiti, mencionando que foram aprovados para a série seguinte, com ausência de carimbo e/ou assinatura de qualquer autoridade escolar de seu 
país. Salientamos que a grande maioria das escolas de Porto Velho não realiza essa avaliação, várias escolas nem aceitam a matrícula porque os imigrantes não possuem documentos 'oficiais' das escolas que estudaram no Haiti. Das três escolas que procuramos, apenas uma aceitou fazer a matrícula das crianças haitianas e realizar o chamado teste de localização, como já dissemos, para saber em qual série a criança deveria estudar. O grande problema é que como essas crianças e adolescentes não sabem a língua portuguesa é muito difícil realizar o teste. Essa dificuldade da língua, fez com que alguns desses adolescentes e crianças ficassem fora da escola em 2015, pois não conseguiram ler em português para realizar a avaliação.

Os adultos alegam que gostariam de continuar do ponto de onde pararam, seja no nível Fundamental ou Médio, porém o que dificulta é a ausência de uma diretriz governamental, como já dissemos, sobre o que fazer nesses casos. O caminho encontrado, o qual temos intermediado, é o recomeço, isto é, uma preparação dos candidatos para se submeterem às provas do sistema de Educação de Jovens e Adultos - EJA - que, no caso de Porto Velho, há uma escola estadual que oferece essa modalidade, sendo que alguns haitianos têm buscado esse recurso. Dessa forma, inicia-se fazendo as provas do $1^{\mathrm{O}}$ ao $5^{\mathrm{o}}$ ano do nível Fundamental I, com as disciplinas de Português, Matemática, Geografia, História e Ciências. Uma vez concluída esta etapa, dá-se início às provas do $6^{\circ}$ ao $9^{\circ}$ ano do nível Fundamental II.

Ao concluir o nível Fundamental II o estudante tem duas opções, opta por um lado, a continuar o processo de fazer as provas por disciplinas, até a conclusão do EM, ou, por outro lado, por fazer apenas o ENEM para pedir a certificação do Ensino Médio, de acordo com os critérios estabelecidos pelo Ministério da Educação e Cultura MEC - e, uma vez de posse do certificado de EM, buscar sua inserção no Ensino Superior.

Quanto ao sistema de Educação para Jovens e Adultos, a modalidade Provão tem se mostrado um caminho menos burocrático, com seu sistema menos complexo, o estudante pode optar pela realização de provas a partir de estudos autônomos ou por acompanhamento das disciplinas, frequentando a escola esporadicamente e realizando, a seu tempo, cada uma das provas das etapas das disciplinas, até concluir uma a uma.

No caso das crianças, são necessários três requisitos para o procedimento da inserção no ambiente escolar. A tradução do documento pessoal - registro de nascimento -, a existência de vaga e falar o vernáculo da escola. A maior barreira é a língua, contudo ela é relativizada, uma vez que percebemos que as crianças são, relativamente, mais rápidas para aprender o português que a média dos adultos. Conhecemos crianças que após 8 meses morando na cidade já falavam o português com desenvoltura. 


\section{REFLEXÕES FINAIS}

Tendo iniciado em 2010, a imigração haitiana para o Brasil chega aos seus 5 anos e, neste tempo, seus desdobramentos são satisfatórios para responder à pergunta da proposta feita pelo tema da redação do Exame Nacional do Ensino Médio - ENEM - em 2012, sobre o Movimento imigratório para o Brasil no século XXI, que teve em um de seus textos de apoio a entrada dos haitianos no país. Após meia década de imigração, o que vemos é um quadro geral no qual há claramente a ausência de uma política migratória no Brasil que contemple as necessidades imediatas dos imigrantes em determinados aspectos, dentre os quais o acesso às instituições de ensino está na base, tanto para os adultos quanto para as crianças.

Os desafios que um país enfrenta, ao permitir que imigrantes entrem e passem a residir em seu território são múltiplos e, como abordamos nesta discussão, a educação faz parte da tônica central que opera em uma via de mão dupla, isto é, para os imigrantes e para a sociedade nacional residente. $O$ problema que encontramos não é causado por falta de instituições, mas pela ausência de uma política ou diretriz sobre o assunto, de maneira que os agentes escolares possam se orientar. Isso é semelhante ao fato de um anfitrião que recebe a visita em sua casa e não tem uma cama para que ele durma e, dessa forma, precisa improvisar. Algumas ações estão em curso em diferentes lugares e, pelo que verificamos, em praticamente todas elas os haitianos contam com o auxílio de pessoas que agem por iniciativas próprias por meio de instituições nãogovernamentais ou governamentais, mas não a partir de uma política que verse sobre a questão.

Num dos casos específicos, a convalidação do certificado/diploma do equivalente ao Ensino Médio brasileiro, o que pode e é possível ser feito é seu reconhecimento consular no Brasil - talvez pelo CNIg ou outra instituição semelhante ou mesmo diferente ligada ao governo federal -, para minimizar os efeitos da burocracia brasileira que exige que o documento seja consularizado na Embaixada brasileira no Haiti, uma vez que muitos dos pretendentes a estudantes encontram-se no Brasil e, para isso, arcará com um custo alto para envio do dos documentos ao país de origem para tal prática.

A experiência das ações localizadas e em curso no Brasil podem, a partir de um intercâmbio de informações entre seus agentes ser, também, fonte para se pensar um documento ou mesmo a criação de um documento de orientação para ações diversas, tanto no âmbito governamental quanto das organizações nãogovernamentais. Para isso, é necessário que haja o empenho dos envolvidos com a imigração haitiana, isto é, haitianos 
migrantes, representantes do Estado haitiano no Brasil, organizações governamentais e não-governamentais, além de empresas que se beneficiam da força de trabalho haitiana no país.

Como alertamos desde o início desse trabalho, a discussão que trazemos não é um direcionamento ou um esclarecimento, pelo contrário, é uma reflexão que chamamos de inaugural em relação ao tema, circunscrito à relação entre a imigração haitiana e as questões sobre a inserção de seus indivíduos no ambiente escolar brasileiro. Nossa pesquisa abrange outras reflexões, porém o que enfatizamos aqui foi apenas um recorte pontual que, por sua vez, oferece-nos um panorama de uma realidade complexa. Dado ao fato de ser uma discussão nova em si mesma, esperamos que a partir dessa reflexão outras abordagens sejam realizadas e trazidas ao público, seja em forma de complementação ou crítica para que possamos, assim, rever pontos de vista - teóricos e políticos - e colaborarmos para a construção de uma realidade que possa, a seu tempo, ser menos dramática para todos os sujeitos envolvidos nesse processo, especialmente àqueles que mais desejam, os imigrantes.

\section{REFERÊNCIAS}

AUDEBERT, Cédric. Immigration et insertion urbaine en Floride: le rôle de la famillie transnationale haïtienne.Revue Européenne des Migrations Internationales. Vol. 20 - $\mathrm{N}^{\mathrm{O}} 3.2004$.

AUDEBERT, Cédric. L'intégration des Antillais en milieu scolaire noir étatsunien: l'exemple des Haïtiens en Floride.EtudesCaribéennes, $\mathrm{n}^{\circ}$ 2, pp. 9-15.2005.

BLACKBURN, Robin. A queda do escravismo colonial: $1776-1848$. Tradução Maria Beatriz Medina. Rio de Janeiro: Record, 2002.

BEAUVOIR, Max. Ervas e energia: o sistema médico holístico do povo haitiano. In. Vodu haitiano: espírito, mito e realidade. Patrick Bellegard-Smith \& Claudine Michel [Org.]. Tradução de Amanda Orlando. Rio de Janeiro: Pallas, 2011.

CASIMIR, Jean.O Haiti e suas elites: o interminável diálogo de surdos. In. Revista Universitas: Relações Internacionais v. 4, n. 2. Brasília: (2012). Tradução Renata de Melo Rosa.

COTINGUIBA, Geraldo Castro. Imigração haitiana para o Brasil: a relação entre trabalho e processos migratórios. Dissertação de Mestrado. Porto Velho/RO: Fundação Universidade Federal de Rondônia/UNIR, 2014. 
COTINGUIBA, Geraldo Castro; PIMENTEL, Marília Lima. Apontamentos sobre o processo de inserção social dos haitianos em Porto Velho. In. Travessia (São Paulo), v. 70, p. 99-106, 2012.

COTINGUIBA, Geraldo Castro; PIMENTEL, Marília Lima. Wout, raketè, fwontyè, anpil mizè: reflexões sobre os limites da alteridade em relação à imigração haitiana para o Brasil. In. Universitas Relações Internacionais, Brasília, v. 12, n. 1, p. 73-86, jan./jun. $2014 a$.

COTINGUIBA, Geraldo Castro; PIMENTEL, Marília Lima. Elementos etnográficos sobre imigração na Amazônia brasileira: inserção social de haitianos em Porto Velho. In. Temas de antropología y migración. Buenos Aires. 2014b. p. 35-53.

COTINGUIBA, Geraldo Castro; PIMENTEL, Marília Lima. Deslocamento populacional contemporâneo: língua e história - uma contribuição para os estudos sobre a imigração haitiana para o Brasil. In. Imigração e deslocamentos populacionais contemporâneos. GATTAZ, André \& FERNANDEZ, Vanessa Paola Rojas (Orgs.). São Paulo: Editora Pontocom, 2015 .

COTINGUIBA, Geraldo Castro; PIMENTEL, Marília Lima; NOVAES, Maria de Lourdes (Org.). Língua portuguesa para haitianos. $1^{\mathrm{a}}$ ed. Florianópolis: SESI. Departamento Regional de Santa Catarina, 2014. 219 p.

DeGRAFF, Michel. Kreyòl Ayisyen, or Haitian Creole ('Creole French'). Disponível em < http://web.mit.edu/ linguistics/people/faculty/degraff/degraff2007hc-ccs. pdf $>$. Acesso em Acessoem 09 fev. 2013.

DEJEAN, Yves. In. SPEARS, Arthur K. (Org.).The Haitian Creole language: history, structure, use, and education. Arthur K. Spears and Carole M. Berotte Joseph. U. K. Lexington Books, 2010.

HANDERSON, Joseph. Diaspora. As dinâmicas da mobilidade haitiana no Brasil, no Suriname e na Guiana Francesa. Tese (Doutorado em Antropologia Social) - PPGAS, Museu Nacional/Universidade Federal do Rio de Janeiro, Rio de Janeiro, 2015.

HURBON, Laënnec. O deus da resistência negra:o vodu haitiano. São Paulo: Paulinas, 1987. Tradução Valdecy Tenório.

GLICK SCHILLER, Nina \& FOURON, Georges E.Georges woke up laughing: long-distance nationalism and the search for home. Duke University Press, New York: 2001. 
JOINT, Louis Auguste. Sistema educacional e desigualdades sociais no Haiti: o caso das escolas católicas. In. Pro-Posições. Campinas, v. 19, n. 2 (56) maio/ago. 2008.

MARCUS, George E. Ethnography in/of the world system: the emergence of multi-sited ethnography. In. Annual Review of Anthropology. Vol 24. 1995 pp. 95117. (JSTOR).

MAUSS, Marcel. Sociologia e antropologia. São Paulo: Cosac Naify, 2003. Tradução Paulo Neves.

NASCIMENTO, Sebastião; THOMAZ, Omar Ribeiro. Da crise às ruínas: impacto do terremoto sobre o ensino superior no Haiti. Brasília: 2010.

NIETO, Carlos. Migración haitiana a Brasil: redes migratorias y espacio social transnacional. $1^{\text {a }}$ ed. Ciudad Autónoma de Buenos Aires: CLACSO, 2014.

RODRIGUES, Luiz Carlos Balga. Francês, crioulo e vodu:a relação entre língua e religião no Haiti. Tese de Doutorado apresentada ao Programa de Pós-Graduação em Letras da Universidade Federal do Rio de Janeiro. Rio de Janeiro, 2008.

ROSA, Renata de Melo. A construção da desigualdade no Haiti:experiências históricas e situações atuais. In. Revista Universitas Relações Internacionais v. 4, n. 2. Brasília: (2006).

SAYAD, Abdelmalek. A imigração ou os paradoxos da alteridade.São Paulo: Editora da Universidade de São Paulo, 1998. Tradução Cristina Murachco.

SEGUY, Franck. A catástrofe de janeiro de 2010, a "internacional comunitária" e a recolonização do Haiti. Tese de doutorado. Universidade Estadual de Campinas. Campinas: Instituto de Filosofia e Ciências Humanas, 2014.

SILVA, Sidney Antonio da.“Aqui começa o Brasil”. Haitianos na Tríplice Fronteira e Manaus. In. _ (Org). Migrações na Pan-Amazônia: fluxos, fronteiras e processos socioculturais.Manaus: Fapeam, 2012.

UNILA - Universidade Federal da Integração LatinoAmericana. Edital no oo4/2014/Proint-Unila, de 17 de dezembro de 2014. 